\title{
Philosophical Foundation of Curriculum Development in Nigeria: The Essencist Model
}

\author{
Samuel Asuquo Ekanem, Ph.D, LLB (Hons),BI \\ Department of Educational Foundations and Administration, Faculty of Education \\ Cross River University of Technology, Calabar- Nigeria \\ email: samaekanem@yahoo.co.uk
}

Ekeng Nyong Ekefre, Ph.D

Department of Educational Foundations and Administration Cross River University of Technology, Calabar-Nigeria

\section{Doi:10.5901/jesr.2014.v4n3p265}

\begin{abstract}
Philosophic issues always have had and still do have serious impact on schools and society. Our contemporary society and the schools are changing basically and in a rapid manner, much more than and it was in the past. There is a fundamental urgency that prompts continuous appraisal and reappraisal of the role of schools, and the demand for philosophy of education. Indeed, without philosophy, educators will have no direction as to what and how to organize and implement whatever we are trying to achieve within the school system. It is an established fact that our philosophy influences and do to a large extent determines our educational decisions, choices and alternatives. This is because curriculum consists of the totality of the environment that the school creates in order to stimulate and guide the wholesome growth and development of the children. This however, could not have been made possible without philosophy. Philosophy provides the starting point in curriculum development as it reflects on the total needs of the children, environment, schools and the society. It is the reflection of the totality of the human socio-economic needs that inspire the contents of curriculum. From this, philosophy becomes the source of the development of curriculum. This paper therefore seeks to establish the philosophical foundation for curriculum from an essencist perspective.
\end{abstract}

\section{Introduction}

Curriculum decisions involve a wide range of considerations that anchor on several issues in education. These issues include the purpose of learning, sources of the subject matter, the nature of teaching/learning process, characteristics of the leaner, among others.

These decisions are based or anchored on certain fundamental beliefs that spring from one's philosophy of education. This is what made it possible for philosophy to be viewed or taken as one of the foundations of curriculum. Other foundational areas of curriculum could be considered to be sociology and psychology.

The various philosophical thoughts that influence curriculum are Idealism, Realism, Existentialism, Pragmatism, Essentialism and Deconstructionism. There is no curriculum that does not draw inspiration from these philosophical schools of thoughts.

Studying philosophy helps us to handle our own personal system of beliefs and values, that is, the way and manner that we perceive the world around us and how we actually define what is important to us. Since philosophical issues have always influenced society and our institutions of learning, the study and understanding of philosophy of education in relation to curriculum development becomes vital and imperative.

Basically, philosophy of education does influence, and to a greater extent determines our educational decisions and alternatives. This is because, those that are responsible for curricular decisions need be clear about what the belief or their belief system. This is based on the fact that unclear or confused beliefs will definitely lead to unclear and confusing curricular. One vital step in developing a personal philosophy of education is to understand the several alternatives that others have develop over the years. Here, we will look into four major philosophical positions that have actually influenced curriculum development but with a strong advocacy for a new philosophical thought and model that we refer to as Essencism. 


\section{Philosophy and the Curriculum Experts}

The philosophy of curriculum experts or specialists do reflect their life experiences, common sense, socio-economic background, education and the general beliefs of the people. A personal philosophy is an evaluation and continuation of the existence of individual growth, development, and learning from experience. Philosophy is and involves a description, explanation and evaluation of the world as perceived from an individual perspective, or through what some social scientists generally refer to as "social lenses".

Curriculum experts do and can turn to several sources of knowledge, but despite the various sources they tap from or the number of authorities they reckon with or listen to, their decisions are often shaped by the totality of the experiences that have affected them and the social group that they identify or inclined to. These decisions are dependent upon the values, attitudes, and beliefs that they have developed over time, which involve their knowledge and interpretation of causes, events and their consequences. It is philosophy that determines the principles for the guiding of actions.

This provides the ground for the notion that no individual can be completely objective in a cultural or social setting, but that curriculum experts can widen their base of knowledge and experiences by making concerted effort to comprehend other sense of values through the analysis of problem from diverse perspectives. There can also be efforts at the modification of their critical analyses and point of view through learning from their experiences and those of others. Those curriculum experts who are not willing to change or modify their points of view or compromise philosophical positions whenever school officials or their colleagues come up with a different philosophy are bound to be at risk of generating conflict and disrupting this school system. Doll (1986) captures this more succinctly when he writes, "Conflict among curriculum planners occurs when persons... hold positions along a continuum of different beliefs and... persuasions". The conflict may get so intense that curriculum study becomes halted. Often times, the differences can be reconciled "temporarily in deference to the demands of a temporary, immediate task". Doll further offer the explanation that " teachers and administrators who are clearly divided in philosophy can seldom work together in close proximity for long periods of time".

The more maturity and understanding a person show, and the fact that such a person is not threatened and "egoinvolved" deeply as a person, the more chances and capability the person has to re-examine and subsequently modify their philosophy, and so will be in a better position to appreciate other people's point of view, for as Socrates capture it, "an unexamined life is not worth living". This position is therefore against the principle of rigidity as it concerns inclination to one's beliefs. This therefore provides a fertile ground for curriculum experts to always take their attitudes and beliefs as being tentative and subject to the Socratic principle of reexamination whenever facts, logic, trends present any challenge to them. It will be very disastrous for curriculum experts to experience or suffer from indecision or lack of any philosophy that can be reflected in an effort to avoid or dulge a commitment to a particular set of values. A high degree of positive construction is very vital and necessary for prudent action. It must however be stated that having a personal philosophy that is tentative and subject to modification does not imply lack of caution, disorganized behavior and disorientation. Curriculum experts can arrive at conclusions based on the evidences that are available, and can as well, alter or change when there are better evidence or superior logic to inspire such changes.

\section{Philosophy as the Tap Root of Curriculum}

The function of philosophy can be seen or taken as the tap root or the starting point in curriculum development. Apart from philosophy being the source of curriculum, it plays other functions in curriculum development. This can be seen in the view of Dewey (1916), when he contends that "philosophy may... be defined as the general theory of education". He further stated that "the business of philosophy is to provide the framework for the aims and method of schools. From the Deweyian perspective, philosophy provides a form of generalized meaning and understanding of our lives. This also moulds our pattern of thinking as he posits that it involves "an explicit formulation of the ... mental and moral attitudes in respect to the difficulties of contemporary social life". It is clear from this that philosophy is not just a starting point for schools; it is equally crucial and fundamental for all curriculum activities. This assertion is supported by Dewey when he posits that "Education is the laboratory in which philosophy distinctions become concrete and are tested"

Greatly influenced by Dewey, Tyler's framework of curriculum also contains philosophy as one of the five criteria generally employed for the selection of educational purposes. The relationship that exists between philosophy and other criteria such as studies of learners, studies of contemporary life, suggestion from subject experts, and the psychology of learning constitute the foundation for the determination of school's purposes. Despite the fact that philosophy is not the 
beginning or starting point of Tylers curriculum, but there exist a strong interaction on an equal basis with other criteria, but he seems to have given prominence to philosophy in the development of educational purposes. This can be seen in Tyler (1949), when he asserts that "The educational and social philosophy to which the school is committed can serve as the first screen for developing the social program... philosophy attempts to define the nature of the good life and a good society... educational philosophies in democratic society are likely to emphasize strongly democratic values in schools".

Indeed, there can exist no serious discourse on philosophy until we accept the question of what is education. When there is agreement on what constitute education, then we can demand to know what the school's purpose is. It is when this is established or done that we can start to pursue philosophy, aims, and goals of curriculum, However, to Goodlan (1979), the very first responsibility of the school is the social order, which he refers to as the "nation-state", but in our culture and society, the sense of individual growth and potential is very paramount and fundamental. The emergence duality, which is the "society versus individual has been a major philosophical issue in western society for centuries and was a very vital issue in Dewey's works. As it can be seen in the claim of Dewey (1916), we do not only desire" to make (good) citizens and worker", but also surely desire "to make human beings who will live life to the fullest".

The creation of a compromise of the duality that exists between national allegiance and individual self fulfillment is therefore a fundamental and sincere aim that should guide all curriculum experts from the means to the ends. This, is due to the fact that when individuals grow and are prosperous, the society will surely flourish. This provides a logical response to the original question posed by Goodlad, since education implies and the society focus for the individual and the society, this becomes a never-ending process of life, and the more refined the guiding philosophy the better quality of the educational process.

In evaluating or considering the influence of philosophic thought on curriculum, there are various classification schemes that are possible but without attaching superiority status to any of the four categories that will be discussed here. Accordingly, we will look at four major philosophical positions that have, hitherto, influenced curriculum development. These are:
a. Idealism
b. Realism
c. Pragmatism
d. Existentialism

\subsection{Idealism}

This philosophical doctrine of idealism holds that matter is an illusion and that reality is that which exists mentally. It champions the notion that moral and spiritual reality as the basic explanation of the world and as a result, regards moral values as been absolute, timeless and universal. The implication of this view to issues of education becomes crucial as this is bound to influence curriculum experts who share in the ideals championed by idealism. So, what role will idealism or its tenets play in the life of teachers or curriculum in education?

Indeed, teachers would function as role models of enduring values. Also, the school will have to be greatly "structured and ought to advocate only those ideas that demonstrate enduring values. The materials used for instructions, therefore would centre on broad ideas particularly those contained in great work of literature and/or scriptures" (Khoso:1-2). Since it is anchored on wide or broad ideas and concepts, idealism differ from the beliefs of those that tend to see learning as the acquisition of specific fact from various advocates of realism that hold the view of the world in relation to object and matter. These proponents believe that human behaviour is rational as far as it is in conformity with the laws of nature and is accordingly guided by social laws. When this is applied to education, there will be a manifestation of those ideas as second possible philosophy of education.

\subsection{Realism}

To the realists, education is a matter of reality rather than speculation. When this is applied to education, the basic responsibility of the teacher then implies the impartation of the learners the knowledge of the world that they live in. In this case, what scholars of various disciplines discovered about the world becomes this knowledge. Also, just like the idealists, the realists equally emphasize that education should show permanent and enduring values that has been transmitted from one generation to the other, without necessarily interfering with the study of other disciplines. The realists see the subject expert as a veritable source and authority for the determination of the curriculum, unlike the idealists that view classics as ideal subject matter that should be studied. 


\subsection{Pragmatism}

Pragmatism is distinctly different from the traditional philosophies such as idealism and realism. As a philosophy, pragmatism anchors on the importance and value of change, process and relativity since it clearly nudged on the fact that the value of an idea is dependent on its actual consequences. To Nash, (1995), the actual consequences are crucial aspects of teaching and learning.

To the pragmatists therefore, learning takes place as the person engages in transacting with the environments. The basic of this interaction is the nature of change. The implication of this is that whatever values and ideas are upheld presently would be regarded as tentative because further social development will definitely alter or change them. As can be drawn as an example, at a particular point in time, it was a general belief that the earth was flat but this was later discredited through scientific research. This can also be seen in the "Geocentric" view of the universe which was later replaced by" Heliocentric" view through Copernicus and other scientists. In consideration therefore, of what is changeless (idealism) and inherited the perceived world or universe (realism,) and to discard social and/or perceptual change becomes detrimental to the general development and growth of the children. This explanation assists us to visualize how pragmatism could influence the framing of curriculum. To the pragmatist, curriculum should be planned in such a manner that it teaches the learner how to think critically instead of what to think. Teaching in this sense should be more exploratory in nature than it being explanatory. Here, learning takes place in an active way since learners solve problem that help them broaden their epistemological horizons and accordingly reconstruct their experiences in consonance with the dynamic or changing world. From this therefore, the question becomes, what then will be the role of the teacher? The role of the teacher will not just be to disseminate information but to construct situations that involves both direct experience with the world of the learner and opportunities provided to comprehend these experiences.

\subsection{Existentialism}

Existentialism as a doctrine holds that there is no values outside human beings, and as such submits that human beings should have the freedom to make choices and then be responsible for the consequences of such choices.

As a philosophy, existentialism suggests that the learners should be put into a number or choice- making situations; this implies that learners should have and be given the freedom to choose what they want to study. This is based on the fact that education must anchor on the perceptions and feelings of the individual in order to facilitate understanding of personal reactions or responses to life situations. The major concern of this process is the individual. Since life is dependent or based on personal meanings, the nature of education, the existentialists maintain should basically be determined by the learner. Individual learner should not in any way be compelled to go into a pre-determined programmes of study. Whatever the learner desires to learn have to be respected and accordingly facilitated by the system. A curriculum that is inspired by existentialism should therefore be made up of experiences and subjects that lend themselves to philosophical dialogue and acts of making choices and emphasis self-expressive activities and media illustrate emotions and insights. This will prompt the teacher to adhere to a non-directive role. The teacher is seen as a partner in the process of learning. Being a professional the teacher functions as a resource person facilitating the individual's search for personal meaning instead of imposition of some predetermined values or interests on learners.

Existentialism though a loose kind of philosophical doctrines or ideas has garnered for itself some levels of popularity. Presently, several educationists talk about focusing on the individual, promoting diversity in the curriculum and emphasis the personal needs and interests of the learners. The autonomy of the learner which is what existentialists adhere to, has been, and still remains the prime characteristic feature of the distance mode of teaching-learning. Due to the explosion in knowledge and the tremendous advancement and growth in information technology, the curriculum of the past appears to be outdated and absolute

To bridge the gap between the needs of the learner, the society and the curriculum content, rethinking in the area of curriculum development seems to be unavoidable. What may seem to be relevant in a given situation need not necessarily always be so. The implication of this is that social changes always require changes in the existing pattern of education. The potentiality that is inherent in the system of distance education aids it to accommodate and cater these changes. It is evident from our discourse that pragmatism and existentialism find ample expression in open distance education.

Basically, each of the four philosophies we have x-rayed starts with a particular view or notion of human nature and of values and truth and accordingly brought out clearly the implications of such a view in relation to curriculum development. Having done this therefore, it is imperative we look at a new philosophy that is modeled to inspire a 
comprehensive restructuring of the Nigerian curriculum development.

\section{Essencism as Our Model}

In our analysis of the four philosophies as they relate to curriculum development and their application in Nigeria we discovered some problems and some of these problems include;

i. Foreign nature of these philosophies: These philosophies that are taught and applied in the Nigerian educational system are imported from other cultures. This makes their application to the Nigerian environment very difficult. This is because any educational philosophy is supposed to be a reflection of the people's culture and values. For instance, the American are known for their pragmatic philosophy, and other Western or European powers are associated with Idealism, Realism and Existentialism. The question then is which of these philosophies is of Nigeria origin? The truth is simply that, all these philosophies are foreign and reflect foreign cultures and values that cannot perfectly suit and satisfy the Nigerian cultural pattern and values.

ii. Metaphysical foundation of the imported philosophies: A critical look at all these philosophies revealed a metaphysics that is distinctly different from that of Nigeria in particular and Africa in general. These philosophies create serious dislocations and separation between man and nature, which tend to negatively affect natural principles and orderings. This in a way denies Nigerian the real logic of natural events.

iii. Lack of comprehensive understanding of these philosophies; Nigerians do not seem to fully understand the inherent logic and internal working of these philosophies. The reason being that no country will reveal to another the real secret of her knowledge and strength.

iv. Incompatibility: These philosophies are very incompatible with Nigeria to derive the basic benefits

v. Dynamics of these philosophies: Inherent in each of the philosophies we looked at, is a dynamism that cannot be denied. The implication of this is that these philosophies keep changing over the years and since they are not home grown, Nigerians seem to be confused with how to apply and adapt to these changes and while pondering and attempting to study and adapt to the new changes, there is another change and this creates confusion and stagnation in the Nigerian system because of the outside dynamics.

Having discovered these problems associated with foreign philosophies it becomes expedient that we develop a philosophy that will be home grown and peculiar to our needs that will seek to satisfy our socio cultural demands and not superimposed foreign ideas. Nigeria needs a philosophy that the citizen will appreciate and understand its internal logic and dynamism, which could be effectively monitored and controlled towards the direction of our desires. This will also help Nigeria to have a single socio-cultural value, which all citizens will pursue to achieve a national goal that this philosophy will define and outline.

The quest for this home grown philosophy leads us to come up with a philosophy that is referred to as Essencism in this paper

Essencism as a philosophy is a coinage from the word "essence" which according to Oxford Dictionary of Philosophy is defined as" The basic or primary element in the being of thing; the thing's nature, or that without which it could not be what it is" (125).

The Oxford Advanced Learner's Dictionary of Current English sees it as "that which makes a thing what it is" (392). This philosophy seeks to highlight the essence of man on planet earth. This is because the philosophies that have been reviewed here tend to diminish the importance of the essence of man as the controller of the habitable earth. Some of these philosophies also attempt to disconnect man from his creator and nature. It seeks to dehumanize and alienate man. Therefore, essencism is a philosophy that sees man as the centrality of all the happenings on earth. Man is the determinant and designer of the world that he lives and controls. This is because, from the biblical era, man was given that divine authority to inherit the earth and dominate it. The book of Genesis made us to understand that God created man in His own image to have both physical and spiritual dominion over all things. Therefore as the last thing that God created before his rest, man represents the Divine Authority of God. Man is God's ambassador and as an ambassador, he is divinely immuned from being harmed by anything on earth. Again, the creation story as contained in the book of Genesis reveals that man was put in the "Garden of Eden" to tend it. Also, we discover that it was" man that provided names for all the animals, trees, birds, shrubs, fruits and all other things, both in the garden and on earth "(Ekanem: 219).

The implication of this is that man is imbued with divine intelligence and knowledge to fulfill God's purpose on earth. It follows then that his education must seek to establish this essence that is those important qualities that make man who his is by God. These qualities of man can be seen in the dual nature of man as both physical and spiritual being. This duality is what constitutes the essence of man. So, the application of this to education will show a curriculum 
that seek to promote this essence of man, which is his duality. This is anchored on the fact that man was created for the purpose of dominating his environment as established by God. So, man's stay in the Garden of Eden was to provide him with a period of divine education to enable him cope and dominate his environment outside the Garden.

This shows that historically, according to Ekanem (2005),"man's education was divinely designed to reflect his techno-nature. This can be seen in man's divine ability to give names to all things created by God without any duplication" (219)."

From this, it can be argued that education of man is divinely inspired. As a result of this inspirational dimension, education seeks to satisfy the spiritual essence of man, while the applied science, which involves technology, actualized the physical manifestation of man's spiritual development.

What can be gleaned from this is that essencism as a philosophy seeks to establish a spiritual foundation for its education. It is this spiritual development that can lead to inspirational advancement of knowledge which practical applicability will lead effortlessly to technological development. This then satisfies the physical essence of man since it is through technological advancement that man is provided with physical comfort. But for the physical comfort to be attained there must be a corresponding spiritual level of development. Also inclusive in this spiritual aspect of man's essence is the ethical value of what is good and bad. This knowledge which essencism will provide will lay bare to all Nigerian citizens and make it possible as a socio-cultural practice that honesty pays.

The application of this to curriculum development will lay a firm foundation for the spiritual development of the learners and provide an ethical system that will emphasis honestly in the learners (children). This will promote the need for good people based education that can sustain our survival as a nation and naturally cure the nation of the ills usually associated with corruption.

\section{Conclusion}

From our discourse, it is clear that there is a nexus between philosophy and curriculum. This is because, when you propose the teaching of a particular body of knowledge, course of subject, you must answer the question, what is your philosophy for introducing that content? Where this vital question is not answered, it will be very difficult to convince others to accept your proposal or idea. This therefore makes philosophy the starting point in any curriculum decision making and is the basis for all subsequent decisions as far as curriculum is concerned. Philosophy from this perspective becomes the criteria for the determination of the aims, selection, organization and implemetation of the curriculum in the classroom.

Indeed, philosophy assists us in providing answers to general questions such as; what are school for? What subjects is value? How should students learn the content?

It is clear that philosophy provides education, especially curriculum workers, with frame or frameworks that assist in the organization of schools and classrooms. It provides them with framework for broad issues and task such as determining the goals of education, the content and its organization, the process of teaching and learning, and in general what experiences and activities they wish to stress in schools and classroom curriculum experts have to understand that they are continuously faced with curriculum decisions, and that philosophy is vital and fundamental in determining these decisions. Curriculum needs to conform to the philosophy of the school and community. Teaching, learning and curriculum are all intertwined in school practices and should accordingly reflect a school's and a community's philosophy. This way, philosophy establishes itself as the foundation of curriculum development. When this is carried out with the essencist perspective the dual nature of man will be developed thereby projecting the spiritual and physical dimensions of man to bring about a creative techno-nature that is imbued with cognitive and affective goodness.

\section{Reference}

Alistair, R. (2000). Curriculum: Construction and Critique. London: Falmer press.

Blackburn, S. (1996) Oxford Dictionary of Philosophy. New York: Oxford University Press.

Brandt, R. S. and Tyler, R. W. (1983) "Goals and Objectives" in F. W. English, ed., Fundamental Curriculum Decisions. Alexandria, VA: Association for Supervision and Curriculum Development.

Dewey, J. (1916) Democracy and Education. New York: Macmillan Pp. 383-384.

Doll, R. C. (1986) Curriculum Improvement: Decision-making and Process, $6^{\text {th }}$ ed. Boston: Allyn and Bacon p.30

Ekanem, S. A. (2005) "A Philosophy of Education for Technological Development in Nigeria" A Doctoral (Ph.D) Dissertation, University of Calabar, Nigeria.

Ekanem, S. A (2013) "Science and Human Nature: A Complex Dynamics of Reality" Mediterranean Journal of Social Sciences, Vol. 4, 
No. 2, May 2013, Pp. $389-400$.

Ekanem, S. A. and Ekefre, E. N. (2013) "Education and Religious Intolerance in Nigeria: The Need for Essencism as a philosophy" Journal of Educational and Social Research, Vol. 3, No 2 May 2013 Pp. 303 - 310.

Goodlad, J. I. (1979). What schools for. Bloomington, IN: Ph.D Delta Kappa Educational Foundation

Goodlad, J. I. (1984). A Place Called School, New York: Mc Graw-His

Heslep, R. (1997). Philosophical Thinking in Educational Practice. London: Greenwood Publishing.

Holy Bible (1989). Authorized King James Version, China: World Publishing.

Hornby, A. S. Oxford Advanced Learner's Dictionary of Current English. New York: Oxford University Press.

Hopkins, L. T. (1941). Interaction: The Democratic Process. Boston: D. C. Health

Ornstein, A. and Huskins, F. (1998). Curriculum: Foundations, Principles and Issues. Boston MA: Allyn and Bason

Smith, B. O., Stanley, W. O., and shores, J. H. (1957). Fundamental of Curriculum. New York: Worldbook.

Tanner, E. and Tanner, L. (1980). Curriculum Development: Theory into Practice. New York: Macmillan Publishing

Tyler, R. W. (1949). Basic Principles of Curriculum and Instruction Chicago: University of Chicago Press. 
